\title{
The importance of healthcare managers' organizational preconditions and support resources for their appraisal of planned change and its outcomes
}

\author{
Jörgen andreasson*1,2, Linda Ahlstrom ${ }^{1,3}$, Andrea Eriksson ${ }^{2}$, Lotta Dellve ${ }^{1,2}$ \\ ${ }^{1}$ Faculty of Caring Science, Work Life and Social Welfare, University of Borås, Sweden \\ ${ }^{2}$ School of Technology and Health, KTH, Royal Institute of Technology, Sweden \\ ${ }^{3}$ Health and Care Sciences, the Sahlgrenska Academy, University of Gothenburg, Sweden
}

Received: October 26, 2016

Accepted: December 8, 2016

Online Published: December 16, 2016

DOI: $10.5430 /$ jha.v6n $1 \mathrm{p} 25$

URL: http://dx.doi.org/10.5430/jha.v6n1p25

\begin{abstract}
Background: Healthcare managers are expected to lead and manage planned organizational change intended to improve healthcare process quality. However, their complex working conditions offer limited decision control, and healthcare managers often feel ill prepared and inadequately supported to perform their duties. Healthcare managers have previously described their need for organizational support, but we lack knowledge of the preconditions and resources that help managers implement planned change.

Methods: This prospective cohort study examined healthcare managers at three Swedish hospitals implementing lean production and two Swedish hospitals implementing their own improvement model. Questionnaire data from 2012, 2103, and 2014 were used in following up. We used $t$-tests and a linear mixed model design in analysing the data.

Results: Healthcare managers who perceived strong support from managers, employees, colleagues, and the organization and managers with the longest managerial experience had the least negative appraisal of change. Managers who perceived strong support from employees, management, and the organizational structure perceived higher levels of healthcare process quality. Conclusions: Long managerial experience and strong support from managers, employees, and the organization are important for managers' appraisal of, work on, and successful implementation of planned change. Top management must therefore ensure that the healthcare managers have sufficient managerial experience and support before they delegate to them the responsibility to implement planned change.
\end{abstract}

Key Words: Healthcare managers, Preconditions, Support resources, Planned change, Healthcare process quality, Appraisal of change

\section{INTRODUCTION}

Numerous attempts have been made to reduce healthcare costs by trying to increase efficiency and improve healthcare quality. ${ }^{[1]}$ First- and second-line managers in Swedish healthcare are expected to lead and manage planned organi- zational change intended to improve quality and efficiency. ${ }^{[2]}$ Despite recent studies of the importance of managers' preconditions and support resources, ${ }^{[3-6]}$ we still lack knowledge of how these managerial conditions affect the outcomes of planned change in healthcare organizations. In this study, we propose that the availability of organizational preconditions

\footnotetext{
*Correspondence: Jörgen andreasson; Email: jorgen.andreasson@hb.se; Address: Faculty of Caring Science, Work Life and Social Welfare; School of Technology and Health, KTH, Royal Institute of Technology, University of Borås, Sweden. 
and organizational support resources affects managers' appraisal of planned change and of the outcomes of this work in terms of improved healthcare process quality. This paper investigates how organizational structural preconditions and organizational support resources affect healthcare managers' appraisal of planned changes and their outcomes in terms of improved healthcare process quality.

\section{BACKGROUND}

Previous research has noted that health care managers play a key role in implementing planned change ${ }^{[2]}$ but that their success in leading such change interacts with other important factors in health care organizations. One such factor is the complexity of healthcare organizations, which are often both centralized (i.e., bureaucratic) and decentralized at the same time. According to Mintzberg, ${ }^{[7]}$ this form of organization is that of the professional bureaucracy. An important aspect of decentralization in the professional bureaucracy is that the involved professionals have considerable control and influence over their own work. This means that, in this organizational structure, managers have limited power to control the professionals working under their supervision. ${ }^{[7]}$ Professional bureaucracies face a big challenge when it comes to embracing new innovations. Accordingly, proposals intended to reduce professional autonomy, for example, the implementation of lean production (henceforth, "Lean"), often meet with resistance, which it is the manager's task to handle. ${ }^{[2]}$ In the professional bureaucracy, handling resistance often requires extensive cooperation between managers and professionals, which tends to be time consuming. ${ }^{[7]}$

Organizational transformation in order to implement Lean will not happen in a healthcare context unless many people advance the process. ${ }^{[8]}$ However, most of the implementation work seems to be about changing manager and employee behavior, ${ }^{[7,9-13]}$ and in healthcare, managers and employees behavior changes interacts with different contextual factors. Accordingly, in this paper we have chosen to apply the Robertson and Porras ${ }^{[9]}$ model of the dynamics of planned organizational change. The model reflects several of the individual contextual factors that interacts with individual behaviour, and assumes that organizations are contexts in which individuals act, and that changes in the organizational work setting can encourage desired behavioural change. The model comprises the following components: intervention activity, organizational work setting, individual behaviour, and organizational outcomes.

\subsection{Intervention activities}

These are the activities by which elements of an organizational work setting are changed. ${ }^{[9]}$ In healthcare, intervention activities for planned change have recently tended to concentrate on increasing the patient focus, including ensuring that the patient's process through the hospital is seamless and without unnecessary disruptions. ${ }^{[14]}$ Recently, applications inspired by the management concept of Lean have become the dominant approach to process improvement addressing patient flows in Sweden. ${ }^{[15]}$ Lean practices commonly include eliminating "waste" by reducing error and "smoothing" process flows to maximize customer value. ${ }^{[16]}$ Rates of successfully implemented interventions for planned change, such as Lean implementation, are under 50\%. ${ }^{[17]}$ Research furthermore demonstrates that supportive leadership and organizational structure, i.e., aspects of the organizational work setting, significantly increase the chances of successful implementation. ${ }^{[8,18]}$

\subsection{Organizational work setting}

According to Robertsson and Porras, ${ }^{[9]}$ the organizational work setting comprises the four subsystems social factors, organizing arrangements, technology, and physical setting. Earlier research demonstrates that aspects of social factors and organizing arrangements are especially important factors hindering planned changes, such as Lean implementation, ${ }^{[19]}$ especially given the managers' difficulties controlling professionals' work in healthcare organizations. ${ }^{\text {[7] }}$

Social factors include the individual and group characteristics of the people in the organization together with their patterns and processes of interaction. ${ }^{[9]}$ People in healthcare organizations are often described as working in silos. ${ }^{\text {[20] }}$ The manager's role has specifically been described as complex, indistinct, and isolated. ${ }^{[21]}$ A study of Swedish healthcare managers found fragmented daily working conditions in which managers must constantly prioritize tasks, ${ }^{[21]}$ with only $3 \%-8 \%$ of their total working time being available for improvement work. ${ }^{[22]}$ First-line managers furthermore often feel poorly prepared and inadequately supported to perform their duties. ${ }^{[23]}$ In this context, the organizational arrangements supporting managers can be assumed to be especially important for helping healthcare managers implement planned changes.

Organizing arrangements encompass the formal elements of the organization, i.e., formal structures and reward systems, created to organize the intervention activities. ${ }^{\text {[9] }}$ For healthcare managers, some of the most critical organizing arrangement factors can be summarized as "organizational structural preconditions" and "organizational support resources".

"Organizational structural preconditions" previously found to be especially important for managerial work are managerial position ${ }^{[24]}$ and managerial experience. ${ }^{[25]}$ For example, 
first-line managers have a higher average number and variety of work activities per day than do second-line managers, ${ }^{[3]}$ while second-line managers have more coherent and longer activities with fewer disruptions. ${ }^{[3]}$ In terms of experience, it usually takes a few years for new managers ${ }^{[5]}$ to build their capacity to handle the variety of work tasks they are faced with, ${ }^{[26]}$ meaning that new managers need more "organizational support resources". [27]

Little healthcare research examines the importance of managers' "supportive organizational structures" for the implementation of planned changes. The "organizational support resources" generally important for managers include supportive top management, supportive manager colleagues, and supportive employees. ${ }^{[6,25]}$ Especially for managers with little experience, such support resources are important for their sustainable health. ${ }^{[26]}$ Several studies describe the importance of good relations and cooperation between managers and employees for the work to be done, ${ }^{[28,29]}$ and they could be regarded as absolute prerequisites for success in implementing planned changes. ${ }^{[2]}$ Demerouti and Bakker ${ }^{[30]}$ demonstrated that having supportive colleagues or managers and getting constructive feedback on one's work can be motivating and increase the possibility of doing good work. Organizational support has also been positively associated with improved performance and care quality in healthcare. ${ }^{[31-33]}$ However, only limited research explores how organizational support resources affect managers' individual behaviour and their appraisal of planned changes and their organizational outcomes.

\subsection{Individual behaviour}

According to the Robertsson and Porras ${ }^{[9]}$ model, individual behaviour is important for the organizational outcomes of planned changes. That is, the behaviour of employees, including managers, in response to planned change efforts can counteract or facilitate the outcomes of a planned change. ${ }^{[9]}$ Handling staff resistance to change is a key issue facing healthcare managers, ${ }^{[7]}$ as without staff help there can be no implementation. ${ }^{[2]}$ Mathena ${ }^{[34]}$ demonstrated that managers can influence their employees' attitudes towards change in healthcare, and that managers' positive attitudes towards change create a work environment that promotes development. ${ }^{[35]}$ It can therefore be assumed that the presence of managers who regard change positively will positively affect organizational outcomes.

\subsection{Organizational outcomes}

According to Robertson and Porras, ${ }^{[9]}$ organizational outcomes include various aspects of organizational performance, such as productivity and job satisfaction (see Figure 1). In

Published by Sciedu Press healthcare, quality of care is one of the most important organizational outcomes. Van den Heuvel ${ }^{[14]}$ found five types of quality in healthcare that can be measured and serve as sources of data for measuring the outcomes of quality improvement work: input quality, healthcare process quality, healthcare product quality, health gain, and patient satisfaction. When studying interventions such as Lean that are intended to improve patient processes, aspects of "healthcare process quality" can be seen as a critical outcome measure.

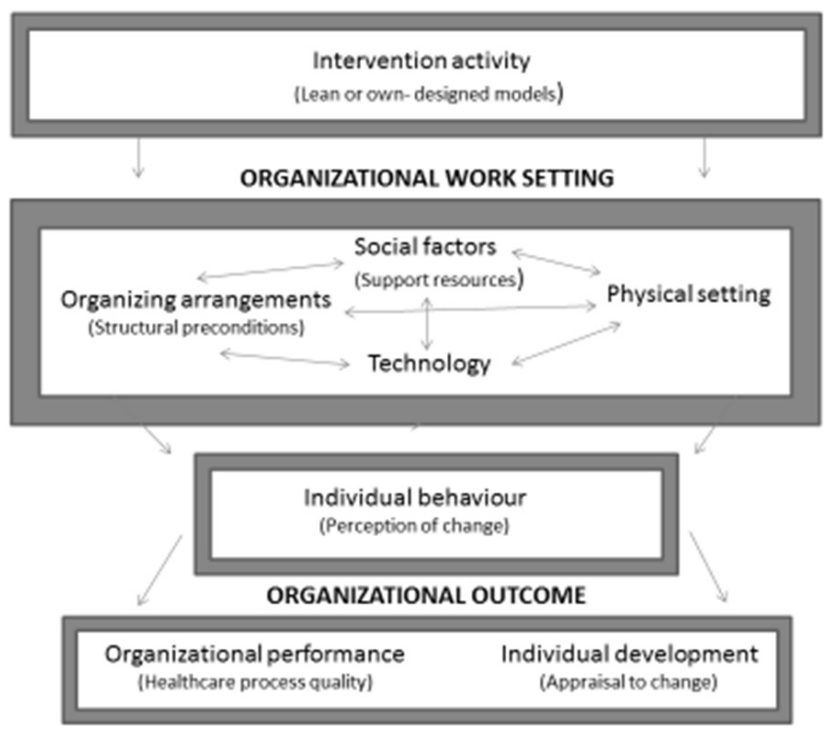

Figure 1. Model of the dynamics of planned organizational change, adapted from Robertson and Porras ${ }^{[9]}$

In summary, previous research demonstrates that more experienced managers at higher managerial levels (i.e., secondline managers), as well as managers strongly supported by their managers, colleagues, and subordinates, may have better preconditions for perceiving change positively and for succeeding with planned organizational changes. More research is needed to investigate the characteristics and conditions of these associations. The hypotheses of this study are therefore as follows:

Hypothesis 1: Managerial experience and second-line position are related to the manager's positive perceptions of improved healthcare process quality.

Hypothesis 2: Managers perceiving strong support from managers, colleagues, employees, and the organizational structure will perceive improved healthcare process quality and will appraise change less negatively.

Hypothesis 3: Managers who tend to appraise change less negatively have higher estimates of improved healthcare process quality. 


\section{METHODS}

This prospective cohort study started in 2012 and included healthcare managers at various levels of five Swedish hospitals. At the time, three hospitals were implementing Lean and two were implementing their own improvement models. The goal of the studied hospitals' activities was largely the same, i.e., to increase efficiency and quality by improving healthcare process quality. ${ }^{[2]}$ The implementation work at the studied hospitals was largely delegated to first- and second-line managers. Yearly questionnaire data were used from three years, i.e., 2012 (T1), 2013 (T2), and 2014 (T3).

\subsection{Sample/participants}

Managers were sampled from five hospitals located in various parts of Sweden; the hospitals differed in size, ranging from approximately 100 to 420 beds. All managers at the participating hospitals were invited to participate.

For inclusion, all participants had to be formally employed as a healthcare manager at the time of recruitment. At T1, 409 eligible participants received questionnaires, and the response rate was $74 \%$ (301 respondents). At T2, 425 questionnaires were delivered and the response rate was 70\% (298 respondents); of these respondents, 212 had also responded in $\mathrm{T} 1$, so 86 were first-time respondents (newly recruited). At T3, 404 questionnaires were delivered and the response rate was $54 \%$ (220 respondents); of these respondents, 42 were new respondents. In total, 429 individuals participated in this study, 129 of whom responded on all three occasions (i.e., T1, T2, and T3). On all measurement occasions, two reminders were sent to the respondents.

Most of the studied managers at T1 (2012) were women $(74 \%, \mathrm{n}=198)$. Most managers were aged $45-54$ years $(38 \%, \mathrm{n}=102)$. The second largest age group comprised those 55 years and older $(36 \%, \mathrm{n}=98)$, while $24 \%$ $(\mathrm{n}=64)$ were $35-44$ years old and only $3 \%(\mathrm{n}=7)$ were $18-34$ years old. Of the women respondents, $55 \%(\mathrm{n}=108)$ were first-line managers, $15 \%(\mathrm{n}=29)$ second-line managers, and $31 \%(n=61)$ managers of a section or development department. Of the men, $37 \%(\mathrm{n}=26)$ were first-line managers, $53 \%(\mathrm{n}=37)$ second-line managers, and $10 \%$ assistant or section managers.

More than half of the managers, $54 \%(\mathrm{n}=142)$, were registered nurses, while the second largest single group, $17 \%$ $(\mathrm{n}=46)$, were managers with backgrounds as physicians. The managers had a variety of educational backgrounds, such as physiotherapy, economics, and psychology. Of the first-line managers, the absolute majority, $79 \%(n=86)$, were registered nurses.

\subsection{Data collection}

The data were collected via web questionnaires comprising approximately 45 questions about manager resources and support, follow-up, improvement work and cost effectiveness, care quality, health, engagement, and work satisfaction. Researchers initially obtained the email addresses of all managers in the selected hospitals from their human resources departments. Coded surveys were used and distributed by email. At T3, there were difficulties with the mail systems at two of the hospitals, so individuals working at those hospitals received paper in addition to emailed questionnaires.

\subsection{Organizational structural preconditions 3.3.1 Managerial position}

This variable was defined as first-line managers, second-line managers, and other kind of managers (e.g., assistant, section, and strategic managers). First-line managers are those closest to the employees who perform the daily operations in a unit. These managers are responsible for a unit, such as a surgical ward or an emergency department. Second-line managers are the first-line managers' supervisors. These managers oversee several units, for example, several surgical wards, in their area of responsibility.

\subsubsection{Managerial experience}

Years as manager in the current position were grouped into three categories: $<2$ years' experience, $<6$ years' experience, and $>7$ years' experience.

\subsection{Organizational support resources}

For measuring managerial stressors and support resources, we used the previously validated instrument, Gothenburg Managers Stress Inventory (GMSI). ${ }^{[3]}$ To measure the variable efficiency in the current sample, indices were created and their internal consistency tested by calculating the Cronbach's alpha.

\subsubsection{Supporting manager colleagues}

This index comprised four items, such as "If needed, I can get good support from manager colleagues" and "I have trusting cooperation with my manager colleagues". The response alternatives ranged from $1=$ very poorly to $5=$ very well. The response scores were dichotomized into two groups: weak support, $<4$ points, and strong support, $>4$ points. ${ }^{[36]}$ The index was tested for internal consistency (Cronbach's alpha $=0.85$ ).

\subsubsection{Supportive management}

This item comprised six items, such as "I get good support from my manager regarding HR questions" and "Upper management shows real interest in what I do and in the kinds of problems I have as a manager". The response alternatives 
ranged from $1=$ very poorly to $5=$ very well. The response scores were dichotomized into two groups: weak support, $<4$ points, and strong support, $>4$ points. ${ }^{[36]}$ The index was tested for internal consistency (Cronbach's alpha $=0.91$ ).

\subsubsection{Supportive organizational structures}

This index comprised seven items, such as "My responsibility and mission as a manager are clear and distinct" and "Rules, policies, and standardization support me well in my managerial role". The response alternatives ranged from $1=$ very poorly to $5=$ very well. The response scores were dichotomized into two groups: weak support, $<4$ points, and strong support, $>4$ points. ${ }^{[36]}$ The index was tested for internal consistency (Cronbach's alpha $=0.80$ ).

\subsubsection{Supportive employees}

This index comprised seven items, such as "I feel that my employees want to take responsibility for their work" and "I have employees that make my work easier". The response alternatives ranged from $1=$ corresponds very poorly to $5=$ corresponds very well. The response scores were dichotomized into two groups: weak support, $<4$ points, and strong support, $>4$ points. ${ }^{[36]}$ The index was tested for internal consistency (Cronbach's alpha $=0.85$ ).

\subsection{Individual appraisal of work on quality improve- ment}

The following five possible answers to the question "If you think about the last six months, how do you perceive the implemented ongoing changes?" were used to create the index negative appraisal of organizational change: "It is time consuming", "I cannot perform my ordinary work tasks as well as I would like", "I am unsure whether I have sufficient competence", "I am unsure whether I can cope", and "There will be tough conflicts in the workplace". The response alternatives were $1=$ no, $2=$ to some extent, and $3=$ yes $($ Cronbach's alpha $=0.66) \cdot{ }^{[37]}$

\subsection{Organizational outcomes: Improved healthcare pro- cess quality}

The index improved healthcare process quality was created using the following five answers to the question "To what extent do you feel that the work in your unit has improved over the last six month regarding ...", "Reduced delays and waiting times for patients", "Increased efficiency" (i.e., less wasted time and unnecessary loss of time), "Improved quality of care", "Increased continuity of care or care processes for patients", and "Increased the chances that patients receive timely care". The response alternatives ranged from $1=$ there has been deterioration to $5=$ to a very great extent $($ Cronbach's alpha $=0.89)$.

Published by Sciedu Press

\subsection{Data analysis}

Descriptive statistics of the background variables and their distributions were calculated, and variables for the factors studied in the cohort are presented in terms of percent, mean, and standard deviation $(S D)$. Data were assumed to be normally distributed, so parametric statistics were used for the analyses. ${ }^{[38]}$ Linear mixed models were used for longitudinal analyses of the repeated measurements. For these analyses, the managers were classified and divided into groups (as explained above). Data from respondents were analysed using JMP 10.0.1 software.

\section{Results}

Approximately three fifths $(61 \%, \mathrm{n}=165)$ of the studied managers were very experienced, having over 7 years of total managerial experience, while approximately one quarter $(26 \%, n=70)$ had $2-6$ years and $13 \%(n=34)$ had $0-2$ years of managerial experience. Of the second-line managers, approximately two thirds $(66 \%, \mathrm{n}=42)$ had over 7 years of managerial experience, while of the first-line managers, 58\% $(n=106)$ had over 7 years of managerial experience.

For all studied managers, the most common support resource was employees and manager colleagues. Strong employee support was perceived by $69 \%(\mathrm{n}=198)$ of managers, while $31 \%(\mathrm{n}=89)$ perceived poor support. About half of the managers, $53 \%(\mathrm{n}=156)$, perceived very good support from manager colleagues, while $47 \%(n=136)$ perceived poor support. Almost two thirds of managers perceived poor support from management $(63 \%, \mathrm{n}=181)$, while over one third, $37 \%$ $(\mathrm{n}=108)$, perceived good support. Organizational support was less common: only $10 \%(\mathrm{n}=27)$ of manager's perceived good organizational support, while $90 \%(n=254)$ perceived poor support.

Managers with the least managerial experience, i.e., $<2$ years, appraised change over time more negatively than managers with $<6$ years of experience (diff. $=0.29$, $\mathrm{SE}=0.09, p$-value $=.001)$ or managers with $>7$ years of experience $($ diff. $=0.23, \mathrm{SE}=0.00, p$-value $=.001)($ see Table 1).

None of the studied organizational precondition variables displayed a direct association with significant changes in healthcare process quality over time.

In addition, the findings indicated that managers who perceived strong support from all studied support variables appraised change less negatively than did managers who perceived weak support. The individuals who reported having supportive managerial colleagues displayed less negative appraisal of change at all measurement points than did managers who perceived weak support (see Figure 2). 
The differences between the two groups were as follows: and from the organizational structure, $0.49, \mathrm{SE}=0.14$, supportive managerial colleagues, diff. $=0.15, \mathrm{SE}=0.05, p$-value $=.0005$ ). Strong perceived support from colleagues $p$-value $=.004 ;$ support from employees, diff. $=0.27$, was also associated with higher perceived healthcare process $\mathrm{SE}=0.05, p$-value $<.001 ;$ support from management, quality over time (diff. $=0.20, \mathrm{SE}=0.11, p$-value $=.079$ ). diff. $=0.16, \mathrm{SE}=0.06, p$-value $=.004$; and support- The results indicated higher perceived healthcare process ive organizational structures, diff. $=0.37, \mathrm{SE}=0.10$, quality among managers who at all measurement points (i.e., $p$-value $=.0005$. Managers who perceived strong support T1-T3) assessed the ongoing changes as not affecting them from employees, management, or the organizational struc- negatively. Managers who appraised the ongoing changes ture perceived higher healthcare process quality in all stud- differently from one measurement point to another, as negaied years than did managers perceiving weak support (from tively affecting them or not, or who appraised the changes employees, diff. $=0.33, \mathrm{SE}=0.14, p$-value $=.019$; from as negatively affecting them on several occasions, did not management, diff. $=0.37, \mathrm{SE}=0.11, p$-value $=.001 ;$ perceive improved healthcare process quality.

Table 1. The studied variables related to outcomes in terms of improved healthcare process quality and negative appraisal of change

\begin{tabular}{|c|c|c|c|c|c|}
\hline & $\begin{array}{l}\text { T1 } \\
\text { LSM (SE) }\end{array}$ & $\begin{array}{l}\text { T2 } \\
\text { LSM (SE) }\end{array}$ & $\begin{array}{l}\text { T3 } \\
\text { LSM (SE) }\end{array}$ & $\begin{array}{l}\text { Difference, group 1-2 } \\
\text { Estimate over time (SE) }\end{array}$ & $\begin{array}{l}\text { Difference, group 1-3 } \\
\text { Estimate over time (SE) }\end{array}$ \\
\hline Managerial experience (T1) & \multicolumn{5}{|c|}{ Improved healthcare process quality } \\
\hline$<2$ years & $3.13(0.11)$ & $3.26(0.15)$ & $3.29(0.23)$ & \multirow{3}{*}{$\begin{array}{l}0.04(0.17) \\
p \text {-value }=.808\end{array}$} & \multirow{3}{*}{$\begin{array}{l}0.09(0.13) \\
p \text {-value }=.518\end{array}$} \\
\hline$<6$ years & $3.09(0.07)$ & $3.17(0.11)$ & $3.09(0.14)$ & & \\
\hline \multirow[t]{2}{*}{$>7$ years } & $3.29(0.05)$ & $3.15(0.06)$ & $3.21(0.08)$ & & \\
\hline & \multicolumn{3}{|c|}{ Negative appraisal of change } & \multirow{4}{*}{$\begin{array}{l}0.29(0.09) \\
p \text {-value }=.001\end{array}$} & \multirow{4}{*}{$\begin{array}{l}0.23(0.09) \\
p \text {-value }=.001\end{array}$} \\
\hline$<2$ years & $2.14(0.06)$ & $2.17(0.08)$ & $2.20(0.12)$ & & \\
\hline$<6$ years & $2.05(0.04)$ & $2.07(0.06)$ & $1.84(0.07)$ & & \\
\hline$>7$ years & $1.92(0.02)$ & $1.97(0.03)$ & $1.90(0.04)$ & & \\
\hline Managerial position (T1) & \multicolumn{3}{|c|}{ Improved healthcare process quality } & \multirow{4}{*}{$\begin{array}{l}0.08(0.11) \\
p \text {-value }=.459\end{array}$} & \multirow{4}{*}{$\begin{array}{l}0.12(0.29) \\
p \text {-value }=.687\end{array}$} \\
\hline First-line manager & $3.27(0.07)$ & $3.38(0.11)$ & $3.12(0.14)$ & & \\
\hline Second-line manager & $3.17(0.04)$ & $3.08(0.06)$ & $3.19(0.08)$ & & \\
\hline \multirow[t]{2}{*}{ Other managers } & $3.50(0.14)$ & $3.12(0.19)$ & $3.39(0.28)$ & & \\
\hline & \multicolumn{3}{|c|}{ Negative appraisal of change } & \multirow{4}{*}{$\begin{array}{l}0.045(0.06) \\
p \text {-value }=.419\end{array}$} & \multirow{4}{*}{$\begin{array}{l}0.28(0.17) \\
\text { p-value }=.095\end{array}$} \\
\hline First-line manager & $1.97(0.04)$ & $1.97(0.06)$ & $1.97(0.07)$ & & \\
\hline Second-line manager & $2.01(0.02)$ & $2.05(0.03)$ & $1.93(0.04)$ & & \\
\hline Other managers & $1.92(0.08)$ & $1.93(0.10)$ & $?$ & & \\
\hline Supportive managerial colleagues ( $\mathrm{T} 1)$ & \multicolumn{3}{|c|}{ Improved healthcare process quality } & \multirow{3}{*}{$\begin{array}{l}0.20(0.11) \\
p \text {-value }=.079\end{array}$} & \multirow{3}{*}{ n.a. } \\
\hline Weak support & $3.10(0.05)$ & $3.06(0.08)$ & $3.13(0.10)$ & & \\
\hline Strong support & $3.32(0.05)$ & $3.24(0.07)$ & $3.25(0.09)$ & & \\
\hline & \multicolumn{3}{|c|}{ Negative appraisal of change } & & \multirow{3}{*}{ n.a. } \\
\hline Weak support & $2.02(0.03)$ & $2.00(0.04)$ & $1.99(0.06)$ & $0.15(0.05)$ & \\
\hline Strong support & $1.96(0.06)$ & $2.02(0.04)$ & $1.87(0.04)$ & $p$-value $=.004$ & \\
\hline Support from employees (T1) & \multicolumn{3}{|c|}{ Improved healthcare process quality } & \multirow{3}{*}{$\begin{array}{l}0.33(0.14) \\
p \text {-value }=.019\end{array}$} & \multirow{3}{*}{ n.a. } \\
\hline Weak support & $3.06(0.06)$ & $3.10(0.10)$ & $2.97(0.13)$ & & \\
\hline Strong support & $3.30(0.05)$ & $3.21(0.06)$ & $3.29(0.08)$ & & \\
\hline & \multicolumn{3}{|c|}{ Negative appraisal of change } & \multirow{3}{*}{$\begin{array}{l}0.27(0.05) \\
p \text {-value }<.001\end{array}$} & \multirow{3}{*}{ n.a. } \\
\hline Weak support & $2.15(0.03)$ & $2.12(0.05)$ & $2.00(0.07)$ & & \\
\hline Strong support & $1.91(0.02)$ & $1.96(0.03)$ & $1.87(0.04)$ & & \\
\hline Support from management (T1) & \multicolumn{3}{|c|}{ Improved healthcare process quality } & & \\
\hline Weak support & $3.10(0.05)$ & $3.07(0.07)$ & $3.05(0.09)$ & $0.37(0.11)$ & \\
\hline Strong support & $3.42(0.06)$ & $3.32(0.08)$ & $3.39(0.09)$ & $p$-value $=.001$ & n.a. \\
\hline & Negative ap & iisal of chang & & & \\
\hline Weak support & $2.05(0.02)$ & $2.02(0.04)$ & $1.94(0.05)$ & $0.16(0.06)$ & \\
\hline Strong support & $1.89(0.03)$ & $1.98(0.04)$ & $1.89(0.05)$ & $p$-value $=.004$ & n.a. \\
\hline Supportive organizational structures (T1) & Improved he & thcare proces. & ality & & \\
\hline Weak support & $3.18(0.04)$ & $3.13(0.06)$ & $3.16(0.07)$ & $0.49(0.14)$ & \\
\hline Strong support & $3.65(0.12)$ & $3.47(0.16)$ & $3.49(0.18)$ & $p$-value $=.0005$ & n.a. \\
\hline & Negative ap & iisal of chang & & & \\
\hline Weak support & $2.01(0.02)$ & $2.04(0.03)$ & $1.95(0.04)$ & $0.37(0.10)$ & \\
\hline Strong support & $1.77(0.06)$ & $1.86(0.09)$ & $1.65(0.10)$ & $p$-value $=.0005$ & n.a. \\
\hline
\end{tabular}

Note. LSM: Least square mean; SE: Standard error; n.a. = not applicable 


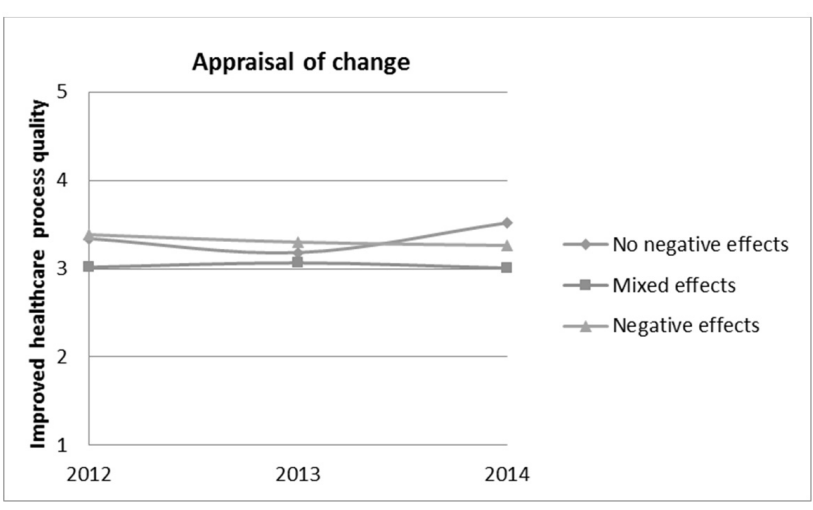

Figure 2. Managers' appraisal of change and improved healthcare process quality (model $p$-value $=.05)$

\section{Discussion}

In this paper, we have chosen to investigate several important factors affecting managerial ability to implement organizational innovations. We also know that implementation and leadership can be affected by several other factors, so our results must be interpreted within the complex healthcare context.

Our findings confirm that managers' experience is important for their appraisal of planned organizational change. It was clear that newer managers had the most negative appraisal of such change; however, as these managers gained experience their negative appraisal of change decreased in intensity (Hypothesis 1). This is in line with previous studies demonstrating that long experience helps managers learn to cope with and prioritize the demands of managerial work. ${ }^{[5,27]}$ The results also indicated that managers who perceived higher support also appraised change less negatively (hypothesis 2) Good leadership support has also previously been found to be important for managers' ability to function in the managerial role. ${ }^{[6,34,39,40]}$ Our study confirms that managers perceiving strong support from employees, management, and the organizational structure perceived higher healthcare process quality (hypothesis 2).

The results indicated that more positive appraisal of planned organizational change increase managers' chances of being able to involve their employees in improvement work and thereby improve healthcare process quality (hypothesis 3 ). This is especially important because healthcare managers are highly dependent on their employees' support when implementing organizational change, such as Lean; also crucial is how the managers with their employees jointly determine to what degree implementation is possible and the pace of the implementation at their unit. ${ }^{[2]}$

In this study, no statistically significant associations were found between organizational structural preconditions and health care process quality. This could be because implementation of, for example, Lean, could lead to short-term deterioration in organizational performance while employees are learning or adapting to new job requirements. ${ }^{\text {[9] }}$ The lack of associations could also relate to the financially constrained environments in which the managers were working. Research has demonstrated that managers working in such environments do not prioritize development programs, instead focusing on their units' core functions. ${ }^{[40]}$ A third explanation is that planned change can take time. We measured respondent perceptions over a three-year period, but the different studied hospitals were at different stages of organizational change implementation, some units having already started, whereas others were only preparing to start. Perhaps the studied hospitals needed more time to improve their healthcare process quality.

Another important factor to take into account when interpreting the present results is that the studied changes were initiated top-down; the first- and second-line managers were then expected to handle the implementation independently and with little support. ${ }^{[2]}$ Top-down approaches can be troublesome in healthcare organizations, where involvement from professional groups is required in order to achieve sustainable change. ${ }^{[2,7,11]}$ With this in mind, we believe that the top-down approach may have made the studied managers even more dependent on their employees during the Lean implementation and processes. ${ }^{[2]}$ This increased dependence meant that the managers had to work even harder to convince resistant employees to participate in implementation. In this effort, managers with long experience were at an advantage because they had had time to build their capacity to handle various tasks. ${ }^{[26]}$ However, the increased managerial dependency on staff may also have made the managers feel supported by their organization, employees, and colleagues, possibly reducing their negative appraisal of change and making them feel that they have a reasonable chance of succeeding in the implementation work.

With this in mind, we suggest that healthcare organizations need to apply a bottom-up approach when implementing planned organizational change. This approach provides opportunities for greater employee involvement, creating preconditions for the emergence of change champions, for participation, and for team-based work in which ideas for change can come from managers as well as employees. ${ }^{[7,12,13,42]}$ To handle the complexity of the implementation process in healthcare, it is important that both managers and employees receive appropriate education about, for example, complex systems ${ }^{[10]}$ so that they will understand the organizational relationships between individuals, the environment, and social processes. This in turn will make it easier to understand the 
implementation context, thereby achieving comprehensive change among healthcare professionals..$^{[10,11]}$

\section{Methodological discussion}

Possible methodological limitations concern selection bias and the outcome measure. The response rates at $\mathrm{T} 1$ and $\mathrm{T} 2$ were good at $70 \%-74 \%$. Despite great effort, however, the same level was not reached at $\mathrm{T} 3$, when the response rate was only $54 \%$. The lower response rate could be because of the length of the questionnaire and certain problems encountered when distributing it. However, these problems were equally distributed among the hospitals and should not affect the questions considered here. We used a sophisticated method to analyse the data, namely, linear mixed models for longitudinal analysis of repeated measurements. The data analysis program handled missing subjects using the remaining available data ${ }^{[41]}$ Another possible limitation could be the outcome measure "health care process quality", which was constructed based on theoretically validated ${ }^{[8]}$ items assembled into an index for the purpose of the present study. The index had good internal consistency but should also be tested for sensitivity in further studies.

\section{Conclusions}

Long managerial experience and strong perceived support from people near the managers are associated with less negative appraisal of change. Strong perceived support from managers, employees, colleagues, and the organization predicts higher perceived levels of healthcare process quality. With this in mind, top management must ensure that the healthcare managers have sufficient managerial experience and support before they delegate the responsibility to implement planned change.

\section{CONFLiCtS OF INTEREST Disclosure}

None.

\section{REFERENCES}

[1] Calltorp J. How can our health system be re-engineered to meet the future challenges? The Swedish experience. Social Science and Medicine. 2012; 74(5): 677-679. https ://doi.org/10.1016/j . socscimed.2011.12.003

[2] Andreasson J, Eriksson A, Dellve L. Health care manager's views on and approaches to implementing models for improving care processes. Journal of Nursing Management. 2015. https : //doi .org/ 10.1111/jonm. 12303

[3] Arman R, Dellve L, Wikström E, et al. What health care managers do: applying Mintzbergs structured observation method. Journal of Nursing Management. 2009; 17(6): 718-729. PMid: 19694915. https://doi.org/10.1111/j.1365-2834.2009.01016.x

[4] Cathcart D, Jeska S, Karnas J, et al. Span of control matters. Journal of Nursing Administration. 2004; 34(9): 395-399. https: //doi.org/10.1097/00005110-200409000-00004

[5] Kerfoot K. Nurse Manager's succession: the process of taking charge. Nurse Economics. 1988; 6(2): 86-87. PMid: 3352810.

[6] Skytt B. First-line nurse managers preconditions for practice: The important Interplay between person and organization [dissertation] Uppsala University. 2007.

[7] Mintzberg H. Structure in fives: Designing effective organizations. Prentice-Hall, Inc. 1993.

[8] Kotter JP. Leading change. Harvard Business Press. 1996.

[9] Robertson PJ, Roberts DR, Porras JI. Dynamics of planned organizational change: Assessing empirical support for a theoretical model. Academy of Management Journal. 1993; 36(3): 619-634. https : //doi.org/10.2307/256595

[10] Kroelinger CD, Rankin KM, Chambers DA, et al. Using the Principles of Complex Systems Thinking and Implementation Science to Enhance Maternal and Child Health Program Planning and Delivery. Maternal and Child Health Journal. 2014; 18(7): 1560-1564. https://doi.org/10.1007/s10995-014-1586-9

[11] Rowe A, Hogarth A. Use of complex adaptive systems metaphor to achieve professional and organizational change. Journal of Ad- vanced Nursing. 2005; 51(4): 396-405. PMid: 16086808. https : //doi.org/10.1111/j.1365-2648.2005.03510.x

[12] Howell JM, Shea CM, Higgins CA. Champions of product innovations: defining, developing, and validating a measure of champion behavior. Journal of Business Venturing. 2005; 20(5): 641-661.

[13] Hendy J, Barlow J. The role of the organizational champion in achieving health system change. Social Science \& Medicine. 2012; 74(3): 348-355. PMid: 21444137. https ://doi.org/10.1016/j.socs cimed.2011.02.009

[14] van den Heuvel J, Niemeijer G, Does J. Measuring healthcare quality: The challenges. International Journal of Healthcare Quality Assurance. 2013; 26(3): 269-278. PMid: 23729130. https: //doi.org/10.1108/09526861311311454

[15] Pokinska B. The Current State of Lean Implementation in Health Care: Literature Review. Quality Management in Health Care. 2010; 19(4): 319-329. https://doi.org/10.1097/QMH.0b013e3181 $\mathrm{fa} 07 \mathrm{bb}$

[16] Womack JP, Jones D. Lean thinking: banish waste and create wealth in your corporation. 2010 Simon and Schuster. https ://doi .org/ 10.1057/palgrave.jors. 2600967

[17] Lee SYD, Alexander JA. Consequences of organizational change in US hospitals. Medical Care Research and Review. 1999; 56(3): 227-276. https : //doi .org/10.1177/107755879905600301

[18] Bliss DEAN. Lean in healthcare-Wow. Frontiers of Health Services Management. 2009; 26(1): 39-42. https://doi.org/10.15358 /9783800646159

[19] Halling B, Wijk K. Experienced barriers to Lean in Swedish Manufacturing and Health Care. International Journal of Lean Thinking. 2013; 4(2).

[20] Mintzberg H. Managing. Berrett-Koehler Publishers. 2009.

[21] Arman R, Wikström E, Tengelin E, et al. Work activities and stress among managers in health care. In Tengblad S (Eds). The Work of Managers; Towards a practice theory of management. Oxford University Press. 2012. 103-126 p. https://doi.org/10.1093/ac prof : oso/9780199639724.003.0006 
[22] Wikström E, Arman R, Dellve L. Vad gör chefer med sin tid och hur kan tid och engagemang hanteras på ett mer hållbart sätt? [What do managers with their time and how can the time and dedication be handled in a more efficient way]. Socialmedicinsk tidskrift. 2013; 90(6): 830-837.

[23] Paliadelis P, Cruickshank M, Sheriden A. Caring for each other: how do nurse managers manage their role. Journal of Nursing Management. 2007; 15(8): 830-837. PMid: 17944609. https: //doi.org/10.1111/j.1365-2934.2007.00754.x

[24] Skagert K, Dellve L, Ahlborg G. A prospective study of manager's turnover and health in a healthcare organization. Journal of Nursing Management. 2012; 20(7): 888-899. PMid: 23050622. https://doi.org/10.1111/j.1365-2834.2011.01347.x

[25] Dellve L, Jutengren G, Ahlborg G. Chefsspecifika stressorer och stödresursers- betydelse för hållbart ledarskap bland chefer i vård och omsorg. [Managerial specific support resources- importance for sustainable leadership among managers in health and social care]. 2014.

[26] Dellve L, Andreasson J, Jutengren G. Hur kan stödresurser understödja hållbart ledarskap bland chefer i vården? [How can support resources support sustainable leadership among managers in healthcare]. Socialmedicinsk tidskrift [Socialmedical Journal]. 2013; 90(6): 866-877.

[27] Cziraki K, McKey C, Peachey G, et al. Factors that facilitate Registered Nurses in their first-line nurse manager role. Journal of Nursing Management. 2014; 22(8): 1005-1014. PMid: 23802630. https://doi.org/10.1111/jonm.12093

[28] Skagert K, Dellve L, Eklöf M, et al. Leader's strategies for dealing with own and their subordinates stress in public human service organizations. Applied Ergonomics. 2008; 39(6): 803-811. PMid: 18222412. https://doi.org/10.1016/j.apergo. 2007. 10.006

[29] Wikström E, Dellve L. Contemporary leadership in healthcare organizations: fragmented or concurrent leadership. Journal of Health Organization and Management. 2009; 23(4): 411-428. PMid: 19862865. https://doi.org/10.1108/14777260910979308

[30] Demerouti E, Bakker AB. The job demands-resources model: Challenges for future research. SA Journal of Industrial Psychology. 2011; 37(2): 1-9. https ://doi.org/10.4102/sajip.v37i2.974

[31] Lachinger HKS, Purdy N, Cho J, et al. Antecedents and consequences of nurse manager's perceptions of organizational support. Nursing Economics. 2006; 24(1): 20.
[32] Laschinger HKS, Wong CA, Grau AL, et al. The influence of leadership practices and empowerment on Canadian nurse manager outcomes. Journal of Nursing Management. 2012; 20(7): 877-888. https://doi.org/10.1111/j.1365-2834.2011.01307.x

[33] Plsek PE, Wilson T. Complexity science: complexity, leadership and management in healthcare organizations. BMJ: British Medical Journal. 2001; 323(7315): 746. https ://doi .org/10.1136/bmj . 323.7315 .746

[34] Mathena KA. Nursing manager leadership skills. Journal of Nursing Administration. 2002; 32(3): 136-142. https ://doi.org/10.109 7/00005110-200203000-00006

[35] Damanpour F. Organizational innovation: A meta-analysis of effects of determinants and moderators. Academy of Management Journal. 1991; 34(3): 555-590. https ://doi .org/10.2307/256406

[36] Eklöf M, Pousette A, Dellve L, et al. Gothenburg Manager Stress Inventory (GMSI). Institute of Stress Medicine Region Västra Götaland. 2010.

[37] Härenstam A, Bejerot E, Leijon P, et al. Multilevel analyses of organizational change and working conditions in public and private sector. European Journal of Work and Organizational Psychology. 2004; 13(3): 305-343. https ://doi.org/10.1080/1359432044 4000119

[38] Altman DG, Royston P. What do we mean by validating a prognostic model? Statistics in medicine. 2000; 19(4): 453473. https://doi.org/10.1002/(SICI) 1097-0258(200002 29) $19: 4<453::$ AID-SIM350>3.0.CO;2-5

[39] Birken SA, Lee SYD, Weiner BJ, et al. Improving the Effectiveness of Health Care Innovation Implementation Middle Managers as Change Agents. Medical Care Research and Review. 2013; 70(1): 29-45. https ://doi .org/10.1177/1077558712457427

[40] Chuang E, Jason K, Morgan JC, et al. implementing complex innovations: Factors influencing middle manager support. Health Care Management Review. 2011; 36(4): 369-379. PMid: 21691212. https://doi.org/10.1097/HMR.0b013e3182100cc2

[41] Twisk J, de Vente W. Attrition in longitudinal studies: how to deal with missing data? J Clin Epidemiol. 2002; 55(4): 329-37. https ://doi.org/10.1016/S0895-4356(01)00476-0.

[42] Pearce C, Conger J. Shared Leadership: Reframing the Hows and Whys of Leadership. Sage Publications. 2002. 